\title{
Short- and long-term outcomes in onco-hematological patients admitted to the intensive care unit with classic factors of poor prognosis
}

\author{
Etienne Faucher ${ }^{1,2}$, Martin Cour ${ }^{1,2}$, Vincent Jahandiez ${ }^{1,2}$, Adeline Grateau ${ }^{1}$, \\ Thomas Baudry', Romain Hernu ${ }^{1}$, Marie Simon ${ }^{1}$, Jean-michel Robert ${ }^{1}$, Mauricette \\ Michallet $^{2,3}$, Laurent Argaud ${ }^{1,2}$ \\ ${ }^{1}$ Hospices civils de Lyon, Groupement hospitalier Edouard Herriot, Service de réanimation médicale, F-69003, Lyon, France \\ ${ }^{2}$ Université de Lyon, Université Lyon 1, Faculté de médecine Lyon Est, F-69008, Lyon, France \\ ${ }^{3}$ Hospices civils de Lyon, Centre hospitalier Lyon-Sud, Service d'hématologie, F-69310, Pierre-Bénite, France \\ Correspondence to: Laurent Argaud, e-mail: laurent.argaud@chu-lyon.fr
}

Keywords: hematological malignancy, allogeneic hematopoietic stem cell transplantation, neutropenia, invasive mechanical ventilation, intensive care unit

Received: October 29, 2015 Accepted: February 23, $2016 \quad$ Published: March 8, 2016

\section{ABSTRACT}

Although the overall mortality of patients admitted to intensive care units (ICU) with hematological malignancy has decreased over the years, some groups of patients still have low survival rates. We performed a monocentric retrospective study including all patients with hematological malignancy in a ten-year period, to identify factors related to the outcome for the whole cohort and for patients with allogeneic hematopoietic stem cell transplantation (HSCT), neutropenia, or those requiring invasive mechanical ventilation (IMV). A total of 418 patients with acute leukemia $(n=239 ; 57 \%)$, myeloma $(n=69 ; 17 \%)$, and lymphoma $(n=53 ; 13 \%)$ were studied. Day-28 and 1-year mortality were $49 \%$ and $72 \%$, respectively. The type of disease was not associated with outcome. The disease status was independentlty associated with 1-year mortality only. Independent predictors of day-28 mortality were IMV, renal replacement therapy (RRT), and performance status. For allogeneic HSCT recipients $(n=116)$, neutropenic patients $(n=124)$ and patients requiring IMV $(n=196)$, day-28 and 1-year mortality were 52\%, 54\%, $74 \%$ and $81 \%, 78 \%, 87 \%$, respectively. Multivariate analysis showed that IMV and RRT for allogeneic HSCT recipients, performance status and IMV for neutropenic patients, and RRT for patients requiring IMV were independently associated with short-term mortality $(p<0.05)$.

These results suggest that IMV is the strongest predictor of mortality in hematological patients admitted to ICUs, whereas allogeneic HSCT and neutropenia do not worsen their short-term outcome.

\section{INTRODUCTION}

The incidence of hematological malignancies has recently been evaluated in Europe as 230,000 new cases per year, with an increasing use of intensive care unit (ICU) resources [1,2]. As a result, intensivists are increasingly faced with managing these patients. The prognosis of onco-hematological patients admitted to ICUs has constantly improved over the last two decades [3]. Progress in diagnostic strategies of acute respiratory failure, in using non-invasive mechanical ventilation (NIMV), and advances in the treatment of the underlying malignancy help to explain this survival gain [4-6]. Consequently, admission policies have become less restrictive and ICUs are able to accept these patients [7].

However, some groups of patients still have a low survival rate. Numerous studies have identified predictors of hospital mortality including neutropenia, hematopoietic stem cell transplantation (HSCT), severity of illness, and organ supports [8-12]. Nevertheless, several concerns 
can be raised. First, prognostic factors evolve over time, which may lead to conflicting results for studies carried out at different periods. Second, in these previous studies, patients with hematological malignancy were not systematically separated from all cancer patients. However, it is well established that their prognostic factors and outcomes are different [13]. Third, as recently confirmed by Azoulay et al., autologous HSCT needs to be dissociated from allogeneic HSCT [12]. Finally, data concerning the long-term outcome of these patients are scarce [3].

Therefore, we conducted this single center retrospective study of a large cohort to assess the recent outcome of patients with hematological malignancy. We focused on both the short- and long-term outcomes of three subgroups of patients with both clinical relevance and classic low survival rate. Thus, we assessed the prognostic factors of patients with neutropenia, allogeneic HSCT, or those requiring invasive mechanical ventilation (IMV). A better understanding of these particular subgroups of patients may help in their management by ICU clinicians.

\section{RESULTS}

\section{Characteristics and outcome of the study population}

A total of 418 patients met the inclusion criteria. Patient characteristics, reasons for ICU admission, organ failures, and day-28 outcome are shown in Table 1. More than 60 patients were admitted in each 2-year period of the study timeframe (Table 2). Age, sex, breakdown of malignancies, SAPS II, use of IMV, and mortality rates were not significantly different across the five periods (Table 2).

Two hundred and seventy-one hematological malignancies (65\%) were high-grade and $147(35 \%)$ were low-grade. Table 3 summarizes a comparison of the patients according to their hematological malignancy. ICU and day-28 mortality for the whole cohort was $46 \%$ (194/418) and 49\% (203/418), respectively. Mortality increased from $58 \%(242 / 418)$ at day-90 to $72 \%(302 / 418)$ at 1 year (Figure 1). The type of hematological malignancy did not influence either the short- or the long-term outcome (Table 3). By multivariate analysis, variables associated with day-28 mortality were IMV (OR, 7.17; 95\% CI, 4.38-11.72), RRT (OR, 2.82; 95\% CI, 1.60-4.99) and performance status (OR per point, 1.48 ; 95\% CI, 1.161.89) (Table 1). Independent predictors of 1-year mortality were performance status, recurrence or progression status, neutropenia, IMV, and RRT (Table 4).

End-of-life decisions were implemented in 78 patients (19\%): 43 (10\%) were intubated, $21(5 \%)$ had neutropenia, and $21(5 \%)$ were allogeneic HSCT recipients. These decisions included no escalation of treatment (not to start treatment if it becomes necessary), withholding (not to start necessary treatment) and withdrawal (to stop necessary treatment). Day-28 mortality for patients with treatment limitation decisions was $73 \%$ (57/78) versus $43 \%$ (146/340) for the population without "do not resuscitate" orders $(p<0.001)$.

\section{Allogeneic hematopoietic stem-cell transplantation recipients}

One hundred and sixteen critically ill allogeneic HSCT recipients ( $28 \%$ of the whole cohort) were included in the study (Table 5). The source of stem cell was bone marrow, peripheral blood, and cord blood in $54 \%(\mathrm{n}=63)$, $36 \%(\mathrm{n}=42)$, and $10 \%$ of patients $(\mathrm{n}=12)$, respectively. Conditioning regimen was myeloablative in 107 patients (92\%). Admission into the ICU occurred during the engraftment period for 40 patients (34\%) and afterwards for 76 patients $(66 \%)$. Sixty patients $(52 \%)$ had GVHD. By univariate analysis, none of these transplantationrelated characteristics significantly influenced the day- 28 mortality. By multivariate analysis, only IMV and RRT were independently associated with short-term outcome (Table 6 and Figure 2).

\section{Neutropenic patients}

Among the 124 patients with neutropenia (30\% of the whole cohort) at ICU admission (see characteristics in Table 5), 85 (69\%) had a white blood cell count lower than $0.1 \times 10^{9} / \mathrm{L}$. Neutropenia followed a course of chemotherapy in 113 patients (91\%). Thirty patients (24\%) experienced neutropenia recovery at the end of their ICU stay. The characteristics of neutropenia had no influence on prognosis (data not shown). Independent predictors of day-28 mortality in this population were IMV and performance status (Table 6 and Figure 3).

\section{Invasive ventilated patients}

During the study period, invasive ventilator support was provided in 196 patients $(47 \%$ of the whole cohort, Table 5). It was the first line treatment in 131 patients $(67 \%)$ while it followed NIMV failure in 65 patients (33\%). One hundred and twenty five patients were initially treated with NIMV in the whole population, with a failure rate of 52\% (65/125). Day-28 mortality was 33\% (20/60) for NIMV success and $77 \%(50 / 65)$ in case of failure of the non invasive procedure. Second-line intubation did not result in a significant excess mortality. One hundred and seven patients (55\%) fulfilled the ARDS criteria. The leading cause of intubation was pneumonia $(\mathrm{n}=98,50 \%)$. Congestive heart failure was diagnosed in 10 patients $(5 \%)$ while 19 patients $(10 \%)$ were intubated for neurological reasons. Multivariate analysis showed that RRT was the only predictor of day-28 mortality in this population (Table 6 and Figure 4). 
Table 1: Patient characteristics according to day-28 outcome

\begin{tabular}{|c|c|c|c|c|c|}
\hline & $\begin{array}{l}\text { All patients } \\
(\mathrm{n}=418)\end{array}$ & $\begin{array}{c}\text { Survivors } \\
(\mathrm{n}=215)\end{array}$ & $\begin{array}{l}\text { Non-survivors } \\
\quad(n=203)\end{array}$ & $\begin{array}{c}\text { Univariate } \\
\text { analysis p Value }\end{array}$ & $\begin{array}{c}\text { Multivariate } \\
\text { analysis p Value }\end{array}$ \\
\hline $\mathrm{Age}^{\mathrm{a}}$ & $55 \pm 15$ & $53 \pm 16$ & $57 \pm 15$ & 0.01 & 0.22 \\
\hline Sex $(\text { male })^{b}$ & $244(58)$ & $128(60)$ & $116(57)$ & 0.62 & \\
\hline Charlson score $^{\mathrm{a}}$ & $4.1 \pm 2.1$ & $3.9 \pm 2.1$ & $4.4 \pm 2.1$ & 0.03 & 0.37 \\
\hline $\mathrm{PS}^{\mathrm{a}}$ & $1.8 \pm 1.0$ & $1.7 \pm 1.0$ & $2.1 \pm 1.0$ & $<0.001$ & $<0.01$ \\
\hline \multicolumn{6}{|l|}{ Hematological malignancies ${ }^{\mathrm{b}}$} \\
\hline Type & & & & 0.35 & \\
\hline Acute leukemia & $239(57)$ & $124(58)$ & $115(57)$ & & \\
\hline Myeloma & $69(17)$ & $34(16)$ & $35(17)$ & & \\
\hline Lymphoma & $53(13)$ & $32(15)$ & $21(10)$ & & \\
\hline Chronic leukemia & $27(6)$ & $14(7)$ & $13(6)$ & & \\
\hline Others & $30(7)$ & $11(5)$ & $19(9)$ & & \\
\hline Disease status & & & & 0.06 & 0.84 \\
\hline Newly diagnosed & $129(31)$ & $63(29)$ & $66(33)$ & & \\
\hline Controlled/Remission & $136(33)$ & $81(38)$ & $55(27)$ & & \\
\hline Recurrence/Progression & $156(37)$ & $71(33)$ & $82(40)$ & & \\
\hline \multicolumn{6}{|l|}{ Treatment/Condition } \\
\hline Autologous HSCT & $43(10)$ & $26(12)$ & $17(8)$ & 0.21 & \\
\hline Allogeneic HSCT & $116(28)$ & $56(26)$ & $60(30)$ & 0.42 & \\
\hline Neutropenia & $124(30)$ & $57(27)$ & $67(33)$ & 0.15 & \\
\hline Reasons for admission ${ }^{\mathrm{b}}$ & & & & 0.02 & NA \\
\hline Respiratory & $199(48)$ & $92(43)$ & $107(53)$ & & \\
\hline Hemodynamic & $112(27)$ & $69(32)$ & $43(21)$ & & \\
\hline Metabolic & $63(15)$ & $36(17)$ & $27(13)$ & & \\
\hline Neurologic & $29(7)$ & $11(5)$ & $18(9)$ & & \\
\hline Cardiac arrest & $6(1)$ & $1(0)$ & $5(2)$ & & \\
\hline Others & $9(2)$ & $6(3)$ & $3(1)$ & & \\
\hline Organ failures $^{\mathrm{b}}$ & & & & $<0.0001$ & NA \\
\hline $\mathrm{n}=0-1$ & 205 (49) & $147(68)$ & $58(29)$ & & \\
\hline $\mathrm{n}=2-3$ & $192(46)$ & $66(31)$ & $124(61)$ & & \\
\hline $\mathrm{n} \geq 4$ & $21(5)$ & $2(1)$ & $19(9)$ & & \\
\hline SOFA score ${ }^{a}$ & $8 \pm 4$ & $7 \pm 3$ & $10 \pm 3$ & $<0.0001$ & NA \\
\hline \multicolumn{6}{|l|}{ Organ supports ${ }^{\mathrm{bc}}$} \\
\hline IMV & $196(47)$ & $51(24)$ & $145(71)$ & $<0.0001$ & $<0.0001$ \\
\hline RRT & $99(24)$ & $26(12)$ & $73(36)$ & $<0.0001$ & $<0.001$ \\
\hline Vasopressors & $214(51)$ & $89(41)$ & $125(62)$ & $<0.0001$ & 0.82 \\
\hline
\end{tabular}




\begin{tabular}{lccccc}
\hline & $\begin{array}{c}\text { All patients } \\
(\mathbf{n = 4 1 8})\end{array}$ & $\begin{array}{c}\text { Survivors } \\
(\mathbf{n = 2 1 5})\end{array}$ & $\begin{array}{c}\text { Non-survivors } \\
(\mathbf{n = 2 0 3 )}\end{array}$ & $\begin{array}{c}\text { Univariate } \\
\text { analysis } \mathbf{p} \text { Value }\end{array}$ & $\begin{array}{c}\text { Multivariate } \\
\text { analysis p Value }\end{array}$ \\
\hline SAPS II $^{\mathrm{a}}$ & $58 \pm 24$ & $46 \pm 16$ & $70 \pm 26$ & $<0.001$ & NA \\
${\text { Length of stay in } \mathrm{ICU}^{\mathrm{a}}}^{10 \pm 15}$ & $12 \pm 19$ & $7 \pm 6$ & $<0.001$ & $\mathrm{NA}$ \\
\hline
\end{tabular}

${ }^{a}$ Data expressed as mean $\pm \mathrm{SD}$.

${ }^{\mathrm{b}}$ Data expressed as number (percentage).

${ }^{c}$ Within the first 48 hours

HSCT: hematopoietic stem cell transplantation; ICU: intensive care unit; IMV: invasive mechanical ventilation; NA: not applicable; NS: not significant; PS: performance status; RRT: renal replacement therapy; SAPS II: simplified acute physiology score II; SOFA: sequential organ failure assessment.

Table 2: Evolution of patients' characteristics and outcome during the study period

\begin{tabular}{|c|c|c|c|c|c|c|}
\hline & $\begin{array}{c}2002-2003 \\
(n=77)\end{array}$ & $\begin{array}{c}2004-2005 \\
(n=108)\end{array}$ & $\begin{array}{c}2006-2007 \\
(n=61)\end{array}$ & $\begin{array}{c}2008-2009 \\
(n=83)\end{array}$ & $\begin{array}{c}2010-2011 \\
(n=89)\end{array}$ & p Value \\
\hline $\mathrm{Age}^{\mathrm{a}}$ & $53 \pm 14$ & $54 \pm 15$ & $57 \pm 14$ & $55 \pm 17$ & $57 \pm 17$ & 0.16 \\
\hline Sex $(\text { male })^{b}$ & $40(52)$ & $65(60)$ & $38(62)$ & $47(57)$ & $54(61)$ & 0.52 \\
\hline \multicolumn{7}{|l|}{$\begin{array}{l}\text { Hematological } \\
\text { malignancies }{ }^{b}\end{array}$} \\
\hline Acute leukemia & $35(45)$ & $72(67)$ & $33(58)$ & $51(61)$ & $48(54)$ & 0.11 \\
\hline Myeloma & $17(22)$ & $18(17)$ & $10(16)$ & $15(18)$ & $9(10)$ & 0.33 \\
\hline Lymphoma & $12(16)$ & $12(11)$ & $6(10)$ & $7(8)$ & $16(18)$ & 0.31 \\
\hline \multicolumn{7}{|l|}{ Treatment/Condition ${ }^{\mathrm{b}}$} \\
\hline Allogeneic HSCT & $20(26)$ & $32(30)$ & $19(31)$ & $20(24)$ & $25(28)$ & 0.81 \\
\hline Neutropenia & $20(26)$ & $33(31)$ & $16(26)$ & $29(35)$ & $26(29)$ & 0.79 \\
\hline $\mathrm{IMV}^{\mathrm{c}}$ & $38(49)$ & $56(52)$ & $25(41)$ & $36(43)$ & $41(46)$ & 0.87 \\
\hline SAPS II ${ }^{\mathrm{a}}$ & $52 \pm 22$ & $58 \pm 25$ & $57 \pm 14$ & $61 \pm 26$ & $59 \pm 20$ & 0.24 \\
\hline Day-28 mortality ${ }^{\mathrm{b}}$ & $37(48)$ & $59(55)$ & $26(43)$ & $42(51)$ & $39(44)$ & 0.75 \\
\hline Day-90 mortality ${ }^{b}$ & $43(56)$ & $67(62)$ & $32(52)$ & $49(59)$ & $51(57)$ & 0.43 \\
\hline 1-year mortality ${ }^{\mathrm{b}}$ & $53(69)$ & $82(76)$ & $41(67)$ & $60(72)$ & $66(74)$ & 0.96 \\
\hline
\end{tabular}

${ }^{a}$ Data expressed as mean $\pm \mathrm{SD}$.

${ }^{\mathrm{b}}$ Data expressed as number (percentage).

${ }^{\mathrm{c}}$ Within the first 48 hours

HSCT: hematopoietic stem cell transplantation; IMV: invasive mechanical ventilation; SAPS II: simplified acute physiology score II.

\section{DISCUSSION}

Of the single-center studies currently available in the literature, this study is one of the largest involving patients with hematological malignancy admitted to an ICU. Additionally, these patients included a large proportion of allogeneic HSCT recipients. We report encouraging (even high) short- and long-term mortality rates that were stable over time. Invasive mechanical ventilation was the strongest predictor of day-28 mortality, whereas allogeneic HSCT or neutropenia did not influence the short-term prognosis of onco-hematological patients. Thus, we advocate that HSCT and neutropenia may no longer be considered as poor prognosis factors in this population of patients.

Our results show that approximately one in two critically ill patients with hematological malignancy died in the acute phase of medical care. This mortality 
Table 3: Most common hematological malignancies-univariate comparison

\begin{tabular}{lcccc}
\hline & $\begin{array}{c}\text { Acute Leukemia } \\
(\mathbf{n}=\mathbf{2 3 9})\end{array}$ & $\begin{array}{c}\text { Myeloma } \\
(\mathbf{n = 6 9 )}\end{array}$ & $\begin{array}{c}\text { Lymphoma } \\
(\mathbf{n}=\mathbf{5 3})\end{array}$ & p Value \\
\hline Age $^{\mathrm{a}}$ & $52 \pm 15$ & $60 \pm 13^{\mathrm{d}}$ & $55 \pm 14^{\mathrm{e}}$ & $<0.001$ \\
Sex (male) & $136(57)$ & $43(62)$ & $32(59)$ & 0.69 \\
Charlson score $^{\mathrm{b}}$ & $3.7 \pm 1.7^{\mathrm{e}}$ & $5.0 \pm 2.4^{\mathrm{d}}$ & $4.4 \pm 2.2^{\mathrm{de}}$ & $<0.001$ \\
PS $^{\mathrm{a}}$ & $1.8 \pm 1.0$ & $2.1 \pm 0.9^{\mathrm{d}}$ & $1.9 \pm 1.0$ & 0.02 \\
Newly diagnosed $^{\mathrm{b}}$ & $103(43)$ & $12(17)^{\mathrm{d}}$ & $11(21)^{\mathrm{d}}$ & $<0.0001$ \\
Autologous HSCT $^{\mathrm{b}}$ & $7(3)$ & $24(35)^{\mathrm{d}}$ & $11(21)^{\mathrm{d}}$ & $<0.0001$ \\
Allogeneic HSCT $^{\mathrm{b}}$ & $61(26)$ & $21(30)$ & $15(28)$ & 0.70 \\
GVHD $^{\mathrm{b}}$ & $31(13)$ & $6(9)$ & $6(11)$ & 0.62 \\
Neutropenia $^{\mathrm{b}}$ & $84(35)$ & $14(20)^{\mathrm{d}}$ & $10(19)^{\mathrm{d}}$ & 0.01 \\
Respiratory distress $^{\mathrm{b}}$ & $122(51)$ & $28(41)$ & $21(40)$ & 0.15 \\
SOFA score $^{\mathrm{a}}$ & $8 \pm 3$ & $8 \pm 4$ & $8 \pm 4$ & 0.13 \\
IMV $^{\text {bc }}$ & $108(45)$ & $31(45)$ & $25(47)$ & 0.96 \\
RRT $^{\text {bc }}$ & $46(22)$ & $20(29)$ & $11(21)$ & 0.22 \\
Vasopressors $^{\mathrm{bc}}$ & $116(49)$ & $29(42)$ & $35(66)^{\mathrm{de}}$ & 0.01 \\
SAPS II $^{\mathrm{a}}$ & $55 \pm 22$ & $62 \pm 28$ & $57 \pm 26$ & 0.12 \\
Day-28 mortality $^{\mathrm{b}}$ & $115(48)$ & $35(51)$ & $21(40)$ & 0.44 \\
Day-90 mortality $^{\mathrm{b}}$ & $130(54)$ & $42(61)$ & $28(53)$ & 0.63 \\
1-year mortality $^{\mathrm{b}}$ & $167(70)$ & $50(72)$ & $35(67)$ & 0.75 \\
\hline
\end{tabular}

${ }^{\text {a }}$ Data expressed as mean $\pm \mathrm{SD}$.

${ }^{\mathrm{b}}$ Data expressed as number (percentage).

${ }^{c}$ Within the first 48 hours.

${ }^{\mathrm{d}} \mathrm{p}<0.05$ compared with leukemia group.

${ }^{\mathrm{e}} \mathrm{p}<0.05$ compared with myeloma group.

GVHD: graft versus host disease; HSCT: hematopoietic stem cell transplantation; IMV: invasive mechanical ventilation;

PS: performance status; RRT: renal replacement therapy.

rate is consistent with other recent studies, which found ICU mortality ranged between $34 \%$ and $61 \%$ [9-11,19]. These results are even more promising as the severity scores of our patients (i.e. SOFA score and SAPS II) were higher than those previously reported $[8,12]$. We found no differences among admission parameters, the type of malignancy, or ventilatory support strategies over the study period. This allowed us to study the cohort as a whole despite the 10-year period. Our ICU cares for more than thirty patients per year with hematological malignancy, which may lead to a greater understanding of specific complications and closer collaborations with hematologists. Indeed, Lecuyer et al. revealed a relationship between case volume and ICU outcome in hematological patients [20]. However, the 1-year mortality rate we observed remained higher than that recently reported by Azoulay et al. in a multicenter study
[12]. In order to explain this difference, we could argue that SOFA score at admission in our cohort was higher and that our refusal rate of patients considered for ICU admission was very low. We acknowledge that one limit is that we did not have data on the ICU admission policy in hematologic ward, which could also impact the outcome in our cohort. Even if determinants of long-term outcome are often difficult to analyze, we can make an assumption. According to our liberal triage protocol, our admission criteria were based on the severity of the illness rather than on the stage of hematological malignancy. Corroborating data suggest that prognosis of malignancy does not predict ICU outcome $[9,21]$. In the present work, one third of the patients admitted to the ICU had an uncontrolled malignancy, which was likely to affect the long-term outcome. Indeed, we showed that the stage of cancer was a strong predictor of 1-year mortality of onco- 
hematological patients. Thus, the subgroup of patients whose malignancy had relapsed or progressed may explain the gap between short- and long-term mortality. However, due to the lack of some information regarding the underlying malignancy, we could not exclude that other characteristics (e.g. cytogenetic data) may also have influenced 1-year outcome.

Our study confirms that invasive ventilation is the main factor that determines short-term outcome in oncohematological patients. The need for intubation has been consistently found to be a factor of poor prognosis in this population [7-13]. Although the notion was controversial, we chose to analyse IMV as a surrogate of respiratory failure rather than a modifiable risk factor. Therefore, we focused on this subgroup with a high risk of mortality and investigated a large cohort of invasively ventilated patients. As previously described, acute respiratory failure was the main reason of admission to the ICU for these patients $[8,9,11,12]$ The ventilation support strategy appears decisive, with mortality rates dramatically different according to the need for intubation. We have described a day-28 mortality of $74 \%$, which is consistent with previous reports. Molina et al. recently showed a $75 \%$ mortality rate in 248 invasively ventilated patients with hematological malignancy [22]. In a large cohort of 717 cancer patients, Azevedo et al. also found that $73 \%$ of patients requiring intubation died in the ICU [23]. High scores for the severity of the illness, the presence of ARDS criteria in most patients, and a low rate of congestive heart failure etiology may explain the poor survival rate we observed. Although NIMV has been shown to decrease mortality, patients with hematological malignancies experience a high failure rate for this technique $[5,7,22,23]$. In our study, as in the literature, nearly half of patients initially treated with NIMV required intubation. Few studies have specifically described prognostic factors for patients with hematological malignancy requiring invasive ventilation [22,24]. Recently, Molina et al. found that allogeneic HSCT, NIMV failure, and APACHE II were independent risks factors that increased mortality [22]. In our study, only RRT was associated with mortality and the presence of allogeneic HSCT did not affect the outcome of ventilated patients.

Among patients with hematological malignancy, allogeneic HSCT recipients are considered to be those who would benefit the least from intensive care treatment. They are usually younger and require higher ICU resources than the other patients $[25,26]$. Their prognosis may be worsened by specific complications, such as GVHD, which require increased immunosuppressive therapy [27]. Over the past twenty years, admissions to the ICU and the initiation of organ support for these patients have raised ethical concerns. In 1996, Rubenfield et al. reported a $100 \%$ mortality rate among mechanically ventilated recipients of bone marrow transplants, questioning the merits of such a technique for these patients [28]. Our results have shown that, today, better survival rates can be achieved for onco-hematological patients with or without allogeneic HSCT, even if they are ventilated. We can assume that early treatment of the respiratory distress, which avoids the delay of intubation, and an adequate triaging strategy can lead to this result. The most recent studies have reported hospital mortality rates ranging from $52 \%$ to $68 \%$ for allogeneic HSCT recipients admitted to

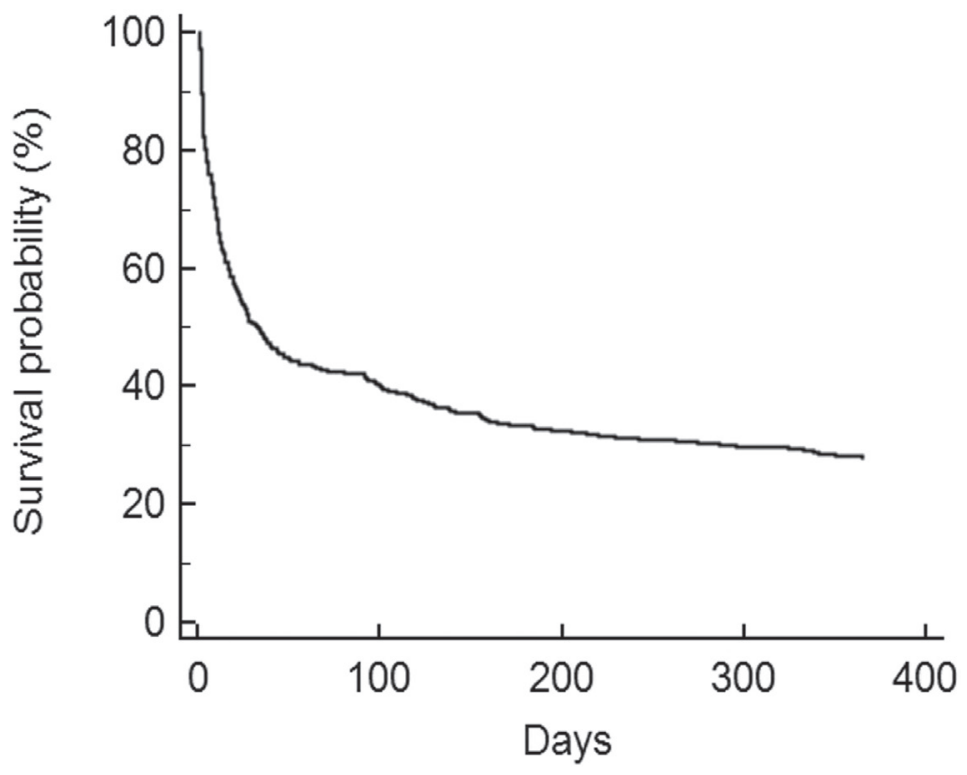

Figure 1: Overall Kaplan-Meier survival curve. 
Table 4: Logistic regression analysis according to 1-year outcome

\begin{tabular}{lccc}
\hline & Odds Ratio & $\mathbf{9 5 \%}$ CI & p Value \\
\hline Age & 1.01 & $0.99-1.03$ & 0.42 \\
Charlson score & 1.12 & $0.93-1.36$ & 0.22 \\
PS (per point) & 1.54 & $1.17-2.03$ & 0.002 \\
Recurrence/Progression & 3.2 & $1.76-5.85$ & $<0.001$ \\
Allogeneic HSCT & 1.78 & $0.93-3.40$ & 0.08 \\
Neutropenia & 1.82 & $1.02-3.27$ & 0.04 \\
IMV $^{\mathrm{a}}$ & 5.49 & $3.09-9.78$ & $<0.0001$ \\
RRT $^{\mathrm{a}}$ & 3.24 & $1.44-7.25$ & 0.004 \\
Vasopressors $^{\mathrm{a}}$ & 1.00 & $0.58-1.70$ & 0.99 \\
\hline
\end{tabular}

a Organ support during the entire ICU stay.

CI: confidence intervals; HSCT: hematopoietic stem cell transplantation; IMV: invasive mechanical ventilation; PS: performance status; RRT: renal replacement therapy.

Table 5: Patient characteristics according to their treatment/condition

\begin{tabular}{lccc}
\hline & $\begin{array}{c}\text { Allogeneic HSCT } \\
(\mathbf{n = 1 1 6})\end{array}$ & $\begin{array}{c}\text { Neutropenia } \\
(\mathbf{n}=\mathbf{1 2 4})\end{array}$ & $\begin{array}{c}\text { IMV }^{\mathbf{c}} \\
(\mathbf{n}=\mathbf{1 9 6})\end{array}$ \\
\hline Age $^{\mathrm{a}}$ & $46 \pm 13$ & $53 \pm 15$ & $55 \pm 16$ \\
Sex(male) & $69(59)$ & $66(53)$ & $105(54)$ \\
Charlson score $^{\mathrm{b}}$ & $3.2 \pm 1.5$ & $3.7 \pm 1.7$ & $4.1 \pm 2.1$ \\
PS $^{\mathrm{a}}$ & $2.1 \pm 1.0$ & $1.8 \pm 0.9$ & $2.0 \pm 1.0$ \\
Newly diagnosed $^{\mathrm{b}}$ & $\mathrm{NA}$ & $43(35)$ & $62(32)$ \\
Autologous HSCT $^{\mathrm{b}}$ & $23(20)$ & $10(8)$ & $17(9)$ \\
Allogeneic HSCT $^{\mathrm{b}}$ & $\mathrm{NA}$ & $38(31)$ & $60(31)$ \\
GVHD $^{\mathrm{b}}$ & $60(52)$ & $8(6)$ & $32(16)$ \\
Neutropenia $^{\mathrm{b}}$ & $38(33)$ & $\mathrm{NA}$ & $61(31)$ \\
Respiratory distress $^{\mathrm{b}}$ & $61(53)$ & $54(44)$ & $105(56)$ \\
SOFA $^{\mathrm{a}}$ & $8 \pm 4$ & $10 \pm 3$ & $10 \pm 3$ \\
IMV $^{\mathrm{bc}}$ & $60(52)$ & $61(49)$ & $\mathrm{NA}$ \\
RRT $^{\mathrm{bc}}$ & $29(25)$ & $30(24)$ & $69(35)$ \\
Vasopressor $^{\mathrm{bc}}$ & $48(41)$ & $77(62)$ & $137(70)$ \\
SAPS II $^{\mathrm{a}}$ & $53 \pm 22$ & $66 \pm 23$ & $70 \pm 26$ \\
Day-28 mortality $^{\mathrm{b}}$ & $60(52)$ & $67(54)$ & $145(74)$ \\
Day-90 mortality $^{\mathrm{b}}$ & $77(66)$ & $80(65)$ & $156(80)$ \\
1-year mortality $^{\mathrm{b}}$ & $94(81)$ & $97(78)$ & $171(87)$ \\
\hline
\end{tabular}

${ }^{a}$ Data expressed as mean $\pm \mathrm{SD}$.

${ }^{\mathrm{b}}$ Data expressed as number (percentage).

${ }^{c}$ Within the first 48 hours.

GVHD: graft versus host disease; HSCT: hematopoietic stem cell transplantation; IMV: invasive mechanical ventilation; PS: performance status; RRT: renal replacement therapy; SAPS II: simplified acute physiology score II; SOFA: sequential organ failure assessment. 
Table 6: Day-28 logistic regression analysis according to the treatment/condition

\begin{tabular}{|c|c|c|c|}
\hline & $\begin{array}{l}\text { Allogeneic HSCT } \\
(n=116)\end{array}$ & $\begin{array}{l}\text { Neutropenia } \\
\quad(n=124)\end{array}$ & $\begin{array}{c}\mathrm{IMV}^{\mathrm{a}} \\
(\mathrm{n}=196)\end{array}$ \\
\hline Charlson score & NA & NA & NS \\
\hline PS (per point) & NS & $1.69[1.04-2.76]^{\mathrm{b}}$ & NA \\
\hline Neutropenia & NA & NA & NS \\
\hline $\mathrm{IMV}^{\mathrm{a}}$ & $4.09[1.80-9.30]^{\mathrm{c}}$ & $9.69[3.86-24.33]^{\mathrm{c}}$ & NA \\
\hline $\mathrm{RRT}^{\mathrm{a}}$ & $3.78[1.34-10.65]^{b}$ & NS & $2.08[1.00-4.33]^{\mathrm{b}}$ \\
\hline Vasopressors $^{\mathrm{a}}$ & NA & NS & NA \\
\hline
\end{tabular}

Data expressed as mortality odds ratio [95\% confidence intervals].

${ }^{a}$ Within the first 48 hours.

${ }^{\mathrm{b}} \mathrm{p}<0.05$;

${ }^{\mathrm{c}} \mathrm{p}<0.001$.

IMV: invasive mechanical ventilation; NA: not applicable; NS: not significant; PS: performance status; RRT: renal replacement therapy.
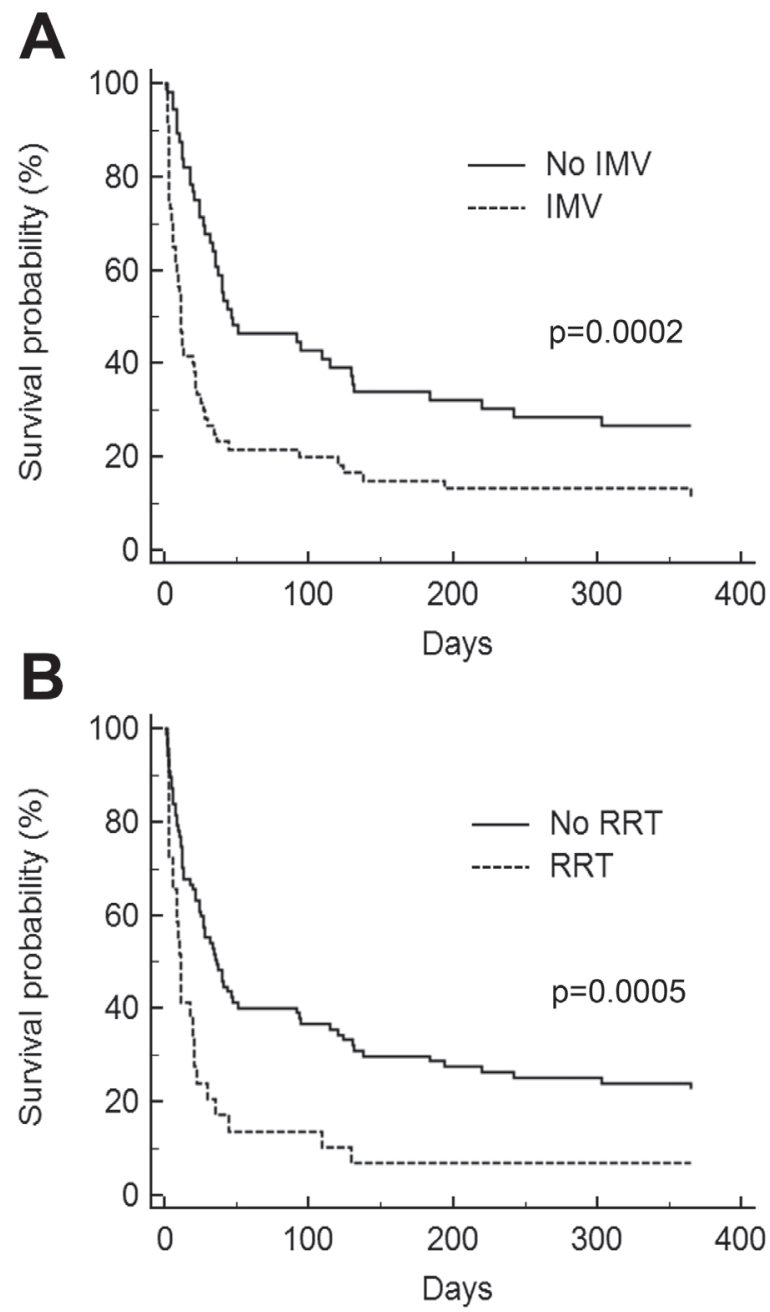

Figure 2: Kaplan-Meier survival curves for allogeneic hematopoietic stem-cell transplantation recipients. A. Invasive mechanical ventilation (IMV). B. Renal replacement therapy (RRT). 
ICUs $[27,28]$. Here, we reported a day-28 mortality rate of $52 \%$, which appears to be an encouraging result since half of the patients were invasively ventilated. In 2006, Pene et al. found mechanical ventilation, corticosteroid treatment for GVHD, and bilirubin levels to be independently associated with mortality [27]. In our cohort of HSCT recipients, only IMV and RRT were predictive of mortality. Nevertheless, we have to underline that a lack of statistical power could be a limit for the analysis of small subgroups, such as patients with GVHD. Thus, we confirm, in the population of allogeneic HSCT recipients, that prognostic factors are mostly related to organ support (i.e. surrogates of organ failure), whereas transplantation characteristics do not appear to impact short-term outcome.

Various studies have also associated neutropenia with mortality among onco-hematological patients admitted to ICUs [9,30,31]. As a result, clinicians are sometimes reluctant to admit neutropenic patients into the ICU and/or to initiate organ support. In fact, literature about critically ill cancer patients gives conflicting results about the impact of neutropenia [9,12,30,31]. Indeed, Souza-Dantas et al., in a match-case controlled study, provided evidence that the presence of neutropenia was no longer associated with worse outcome among cancer patients [32]. In a large prospective cohort of oncohematological patients, Azoulay et al. confirmed that neutropenia was not associated with short-term outcome [12]. Our results, consistent with these recent studies, contribute to the closing of the debate [12,32]. Low levels of white blood cells should be added to the list of classic mortality predictors which are no longer relevant, such as the type of malignancy, the disease status, recent bacteriemia, or chemotherapy $[9,33]$. We reported here a $54 \%$ mortality rate at day-28 for this subgroup of patients. Legrand et al., in a cohort of 428 critically ill patients with neutropenia, reported a $50 \%$ hospital mortality rate,

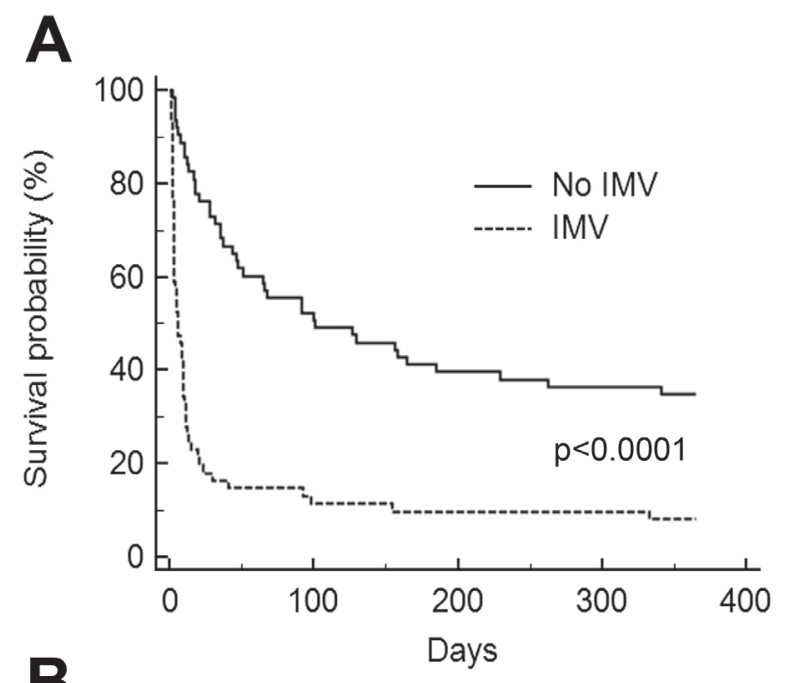

B

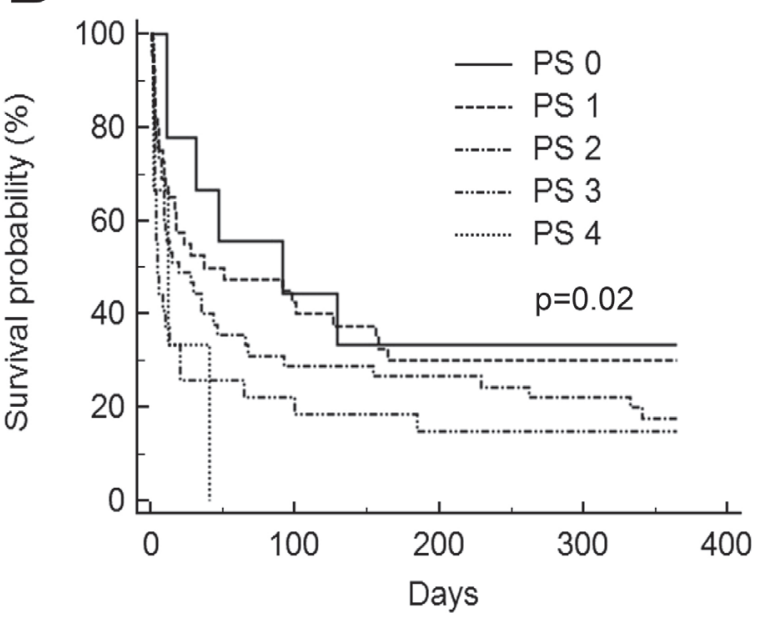

Figure 3: Kaplan-Meier survival curves for neutropenic patients. A. Invasive mechanical ventilation (IMV). B. Performance status (PS). 
decreasing along the study period [34]. This is consistent with the mortality rates we observed, even if we did not observe an improvement in survival over the ten-year period we studied. In addition to IMV, performance status was also an independent predictor of day-28 mortality for our cohort. Indeed functional assessment on admission was found to be a key prognostic factor in some previous studies [12]. Interestingly, performance status is all the more relevant as it is easily assessed for all patients upon admission in all patients.

In summary, our results are both encouraging and disturbing. Our study confirms a low survival rate for patients with hematological malignancy requiring IMV. Our data also support the fact that neutropenia is no longer associated with short-term mortality and that an encouraging mortality rate can be achieved for HSCT recipients. Ventilatory support strategies definitely play a key role in patient outcome and efforts should be made to limit the need for intubation without delaying it.

\section{MATERIALS AND METHODS}

\section{Design, setting and patients}

The ethics committee, Comité de Protection des Personnes Sud-Est II, approved this retrospective noninterventional study. The need for consent was waived given the retrospective design of the project. The study was performed in compliance with the ethical standards of the Declaration of Helsinki and according to French laws.

The study was conducted in a 15-bed universityaffiliated adult medical ICU. From January 2002 to
December 2011, all adult patients ( $\geq 18$ years old) admitted to the ICU with hematological malignancy were included. In our hospital, all patients with cancer were eligible for ICU admission unless explicit advanced directives were present. Admission policy was not restrictive.

\section{Data collection and definitions}

Variables collected within the first $24 \mathrm{~h}$ of ICU admission included: age, gender, comorbidities according to the Charlson score [14], performance status [15], type of malignancy, disease status, bone marrow transplant status (type, conditioning regimen), presence of graft versus host disease (GVHD), neutropenia, reason for admission, and severity of illness (according to both SOFA score [16] and SAPS II [17]). Type of organ support (IMV, NIMV, renal replacement therapy, RRT and vasopressors) was collected within the first 48 hours and during the entire ICU stay. Mortality was evaluated at day-28, day-90, and 1 year.

As previously described, high-grade malignancies included acute leukemia and aggressive lymphoma, whereas low-grade malignancies included chronic leukemia, indolent lymphoma, myeloma, Waldenström macroglobulinemia, and aplastic anemia [9]. Disease status was defined by a hematologist prior to ICU admission and included newly diagnosed ( $<4$ weeks), controlled/ remission, or recurrence/progression. Neutropenia was defined as a leukocyte cell count $<0.5 .10^{9} / \mathrm{L}$. Bone marrow transplants were autologous or allogeneic. The recorded reason for admission was based on the main symptom upon being admitted into the ICU. According to the SOFA, each organ failure was defined by a score $>2$

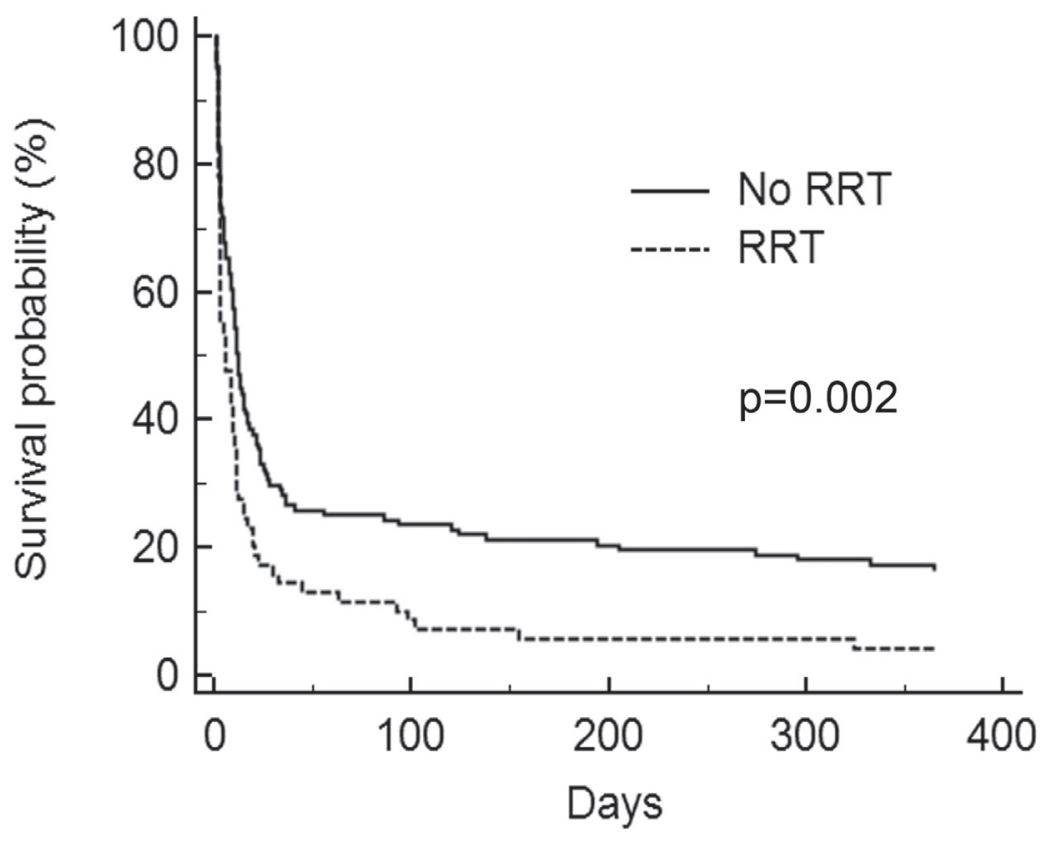

Figure 4: Kaplan-Meier survival curves for invasive ventilated patients. RRT: renal replacement therapy. 
[16]. Diagnosis of ARDS was made in accordance with the 1994 American-European consensus-conference [18].

\section{Statistical analysis}

Values are expressed as mean \pm standard deviation (SD) and number (percentage), as appropriate.

Clinical data were first compared in two-year periods over the timeframe of the study. Data were also compared according to the type of hematological malignancy. Comparisons were carried out using a oneway analysis of variance (ANOVA) for continuous data and the chi-squared test for categorical variables.

Prognostic variables in determining day- 28 and 1 -year mortality were assessed by univariate analyses using an unpaired Student's t-test for continuous data and the chi-squared test or fisher's exact test for categorical data, as appropriate. All variables with $p<0.15$ were included in multivariate analysis using a logistic regression model. As we chose to evaluate the impact of organ support, the reason for admission, SOFA, and SAPS 2 were excluded from the model because of redundancy. Odds ratios (OR) were estimated with $95 \%$ confidence intervals $(95 \% \mathrm{CI})$. Initial analyses included the whole cohort. Depending on day-28 outcome, patients were also analyzed according to treatment/condition details (allogeneic HSCT, neutropenia, IMV). Each of these three subgroups underwent univariate and multivariate analysis similar to that described above. These analyses were performed independently but the groups were not mutually exclusive.

Time to death for the whole cohort and for the 3 predefined subgroups of patients were modeled by means of Kaplan-Meier estimates, and differences were compared by use of the log-rank test.

Statistical calculations were performed using Medcalc Software version 7.4.3.0 (Mariarke, Belgium). Differences were considered significant when $\mathrm{p}<0.05$.

\section{ACKNOWLEDGMENTS}

None.

\section{CONFLICTS OF INTEREST}

The authors declare that they have no conflicts of interest.

\section{GRANT SUPPORT}

None.

\section{REFERENCES}

1. Rodriguez-Abreu D, Bordoni A, Zucca E. Epidemiology of haematological malignancies. Ann Oncol. 2007; 18: i3-i8.
2. Taccone FS, Artigas AA, Sprung CL, Moreno R, Sakr Y, Vincent JL. Characteristics and outcome of cancer patients in european ICUs. Crit Care. 2009; 13: R15.

3. Azoulay E, Soares M, Darmon M, Benoit D, Pastores $\mathrm{S}$, Afessa B. Intensive care of the cancer patient: recent achievements and remaining challenges. Ann Intensive Care. 2011; 23: 5 .

4. Azoulay E, Mokart D, Rabbat A, Pene F, Kouatchet A, Bruneel F, Vincent F, Hamidfar R, Moreau D, Mohammedi I, Epinette G, Beduneau G, Castelain V et al. Diagnostic bronchoscopy in hematology and oncology patients with acute respiratory failure: prospective multicenter data. Crit Care Med. 2008; 36: 100-107.

5. Hilbert G, Gruson D, Vargas F, Valentino R, GbikpiBenissan G, Dupon, M Reiffers J, Cardinaud JP. Noninvasive ventilation in immunosuppressed patients with pulmonary infiltrates, fever, and acute respiratory failure. $\mathrm{N}$ Engl J Med. 2001; 344: 481-487.

6. Pulte D, Gondos A, Brenner H. Improvements in survival of adults diagnosed with acute myeloblastic leukemia in the early 21 st century. Haematologica. 2008; 93: 594-600.

7. Lecuyer L, Chevret S, Thiery G, Darmon M, Schlemmer B, Azoulay E. The ICU trial: a new admission policy for cancer patients requiring mechanical ventilation. Crit Care Med. 2007; 35: 808-814.

8. Kroschinsky F, Weise M, Illmer T, Haenel M, Bornhaeuser M, Hoeffken, G Ehninger G, Schuler U. Outcome and prognostic features of intensive care unit treatment in patients with hematological malignancies. Intensive Care Med. 2002; 28: 1294-1300.

9. Benoit DD, Vandewoude KH, Decruyenaere JM, Hoste EA, Colardyn FA. Outcome and early prognostic indicators in patients with a hematologic malignancy admitted to the intensive care unit for a life-threatening complication. Crit Care Med. 2003; 31: 104-112.

10. Hampshire PA, Welch CA, McCrossan LA, Francis K, Harrison DA. Admission factors associated with hospital mortality in patients with haematological malignancy admitted to UK adult, general critical care units: a secondary analysis of the ICNARC Case Mix Programme Database. Crit Care. 2009; 13: R137.

11. Bird GT, Farquhar-Smith P, Wigmore T, Potter M, Gruber PC. Outcomes and prognostic factors in patients with haematological malignancy admitted to a specialist cancer intensive care unit: a 5 yr study. Br J Anaesth. 2012; 108: 452-459.

12. Azoulay E, Mokart D, Pène F, Lambert J, Kouatchet A, Mayaux J, Vincent F, Nyunga M, Bruneel F, Laisne LM, Rabbat A, Lebert C, Perez P et al. Outcomes of critically ill patients with hematologic malignancies: prospective multicenter data from France and Belgium--a groupe de recherche respiratoire en réanimation onco hématologique study. J Clin Oncol. 2013; 31: 2810-2018.

13. Oeyen SG, Benoit DD, Annemans L, Depuydt PO, Van Belle SJ, Troisi RI, Noens LA, Pattyn P, Decruyenaere 
JM. Long-term outcomes and quality of life in critically ill patients with hematological or solid malignancies: a single center study. Intensive Care Med. 2013; 39: 889-898.

14. Charlson ME, Pompei P, Ales KL, MacKenzie CR. A new method of classifying prognostic comorbidity in longitudinal studies: development and validation. J Chronic Dis. 1987; 40: 373-383.

15. Oken MM, Creech RH, Tormey DC, Horton J, Davis TE, McFadden ET, Carbone PP. Toxicity and response criteria of the eastern cooperative oncology group. Am J Clin Oncol. 1982; 5: 649-655.

16. Vincent JL, de Mendonca A, Cantraine F, Moreno R, Takala J, Suter PM, Sprung CL, Colardyn F, Blecher S.Use of the SOFA score to assess the incidence of organ dysfunction/failure in intensive care units: results of a multicenter, prospective study. Crit Care Med. 1998; 26: 1793-1800.

17. Le Gall JR, Lemeshow S, Saulnier F. A new Simplified Acute Physiology Score (SAPSII) based on a European/ North American multicenter study. JAMA. 1993; 270: 2957-2963.

18. Bernard GR, Artigas A, Brigham KL, Carlet J, Falke K, Hudson L, Lamy M, Legall JR, Morris A, Spragg R. Report of the American-European consensus conference on ARDS: definitions, mechanism, relevant outcomes and clinical trial coordination. The consensus committee. Intensive Care Med. 1994; 20: 225-232.

19. Bernal T, Pardavila EV, Bonastre J, Jarque I, Borges M, Bargay J, Ayestarán JI, Insausti J, Marcos P, GonzálezSanz V, Martínez-Camblor P, Albaiceta GM. Survival of hematological patients after discharge from the intensive care unit: a prospective observational study. Crit Care. 2013; 17: R302.

20. Lecuyer L, Chevret S, Guidet B, Aegerter P, Martel P, Schlemmer B, Azoulay E. Case volume and mortality in haematological patients with acute respiratory failure. Eur Respir J. 2008; 32:748-754.

21. Massion PB, Dive AM, Doyen C, Bulpa P, Jamart J, Bosly A, Installe E. Prognosis of hematologic malignancies does not predict intensive care unit mortality. Crit Care Med. 2002; 30: 2260-2270.

22. Molina R, Bernal T, Borges M, Zaragoza R, Bonastre J, Granada RM, Rodriguez-Borregán JC, Núñez K, Seijas I, Ayestaran I, Albaiceta GM; the EMEHU study investigators. Ventilatory support in critically ill hematology patients with respiratory failure. Crit Care. 2012; 16: R133.

23. Azevedo LC, Caruso P, Silva UV, Torelly AP, Silva E, Rezende E, Netto JJ, Piras C, Lobo SM, Knibel MF, Teles JM, Lima RA, Ferreira BS et al. Outcomes for Patients with Cancer Admitted to the ICU Requiring Ventilatory Support: Results from a Prospective Multicenter Study. Chest. 2014; 146: $257-266$
24. Gristina GR, Antonelli M, Conti G, Ciarlone A, Rogante S, Rossi C, Bertolini G; GiViTI (Italian Group for the Evaluation of Interventions in Intensive Care Medicine). Noninvasive versus invasive ventilation for acute respiratory failure in patients with hematologic malignancies: a 5-year multicenter observational survey. Crit Care Med. 2011; 39: 2232-2239.

25. Kress JP, Christenson J, Pohlman AS, Linkin DR, Hall JB. Outcomes of critically ill cancer patients in a university hospital setting. Am J Respir Crit Care Med. 1999; 160: 1957-1961.

26. Merz TM, Schär P, Bühlmann M, Takala J, Rothen HU. Resource use and outcome in critically ill patients with hematological malignancy: a retrospective cohort study. Crit Care. 2008; 12: R75.

27. Pene F, Aubron C, Azoulay E, Blot F, Thiery G, Raynard B, Schlemmer B, Nitenberg G, Buzyn A, Arnaud P, Socié G, Mira JP. Outcome of critically ill allogeneic hematopoietic stem cell transplantation recipients: a reappraisal of indications for organ failure supports. J Clin Oncol. 2006; 24: 643-649.

28. Rubenfeld GD, Crawford SW. Withdrawing life support from mechanically ventilated recipients of bone marrow transplants: a case for evidence-based guidelines. Ann Intern Med. 1996; 125: 625-633.

29. Soubani AO, Kseibi E, Bander JJ, Klein JL, Khanchandani G, Ahmed HP, Guzman JA. Outcome and prognostic factors of hematopoietic stem cell transplantation recipients admitted to a medical ICU. Chest. 2004; 126: 1604-1611.

30. Vallot F, Paesmans M, Berghmans T, Sculier JP. Leucopenia is an independent predictor in cancer patients requiring invasive mechanical ventilation: a prognostic factor analysis in a series of 168 patients. Support Care Cancer. 2003; 11: 236-241.

31. Owczuk R, Wujtewicz MA, Sawicka W, Wadrzyk A, Wujtewicz M. Patients with haematological malignancies requiring invasive mechanical ventilation: differences between survivors and non-survivors in intensive care unit. Support Care Cancer. 2005; 13: 332-338.

32. Souza-Dantas VC, Salluh JI, Soares M. Impact of neutropenia on the outcomes of critically ill patients with cancer: a matched case-control study. Ann Oncol. 2011; 22: 2094-2100.

33. Vandijck DM, Benoit DD, Depuydt PO, Offner FC, Blot SI, Van Tilborgh, AK Nollet J, SteelE, Noens LA, Decruyenaere JM. Impact of recent intravenous chemotherapy on outcome in severe sepsis and septic shock patients with hematological malignancies. Intensive Care Med. 2008; 34: 847-855.

34. Legrand M, Max A, Peigne V, Mariotte E, Canet E, Debrumetz A, Lemiale V, Seguin A, Darmon M, Schlemmer B, Azoulay E. Survival in neutropenic patients with severe sepsis or septic shock. Crit Care Med. 2012; 40: 43-49. 